\title{
PLLA-PEG-TCH-labeled bioactive molecule nanofibers for tissue engineering
}

This article was published in the following Dove Press journal:

International Journal of Nanomedicine

20 October 20II

Number of times this article has been viewed

\author{
Jun Chen ${ }^{1,2}$ \\ Beth Zhou ${ }^{1-3}$ \\ Qi $\mathrm{Li}^{1,2}$ \\ Jun Ouyang ${ }^{4}$ \\ Jiming Kong 2,4,5 $^{2,6}$ \\ Wen Zhong 3,6 \\ Malcolm MQ Xing 1,2,4,7 \\ 'Department of Mechanical \\ Engineering, Faculty of Engineering, \\ University of Manitoba, Winnipeg, \\ MB, Canada; ${ }^{2}$ Manitoba Institute \\ of Child Health, Winnipeg, MB, \\ Canada; ${ }^{3}$ Department of Textile \\ Sciences, Faculty of Human Ecology, \\ University of Manitoba, Winnipeg, \\ MB, Canada; ${ }^{4}$ School of Basic Medical \\ Science, Southern Medical University, \\ Guangzhoug, China; ${ }^{5}$ Department of \\ Human Anatomy and Cell Sciences, \\ ${ }^{6}$ Department of Medical Microbiology, \\ Faculty of Medicine, ${ }^{7}$ Department of \\ Biochemistry and Medical Genetics, \\ Faculty of Medicine, University of \\ Manitoba, Winnipeg, MB, Canada
}

Correspondence: Malcolm MQ Xing Department of Mechanical Engineering, 75A Chancellors Circle, University of Manitoba,Winnipeg, MB R3T 5V6, Canada Tel +l 204480 I396

Fax + I 2042757507

Email xing@cc.umanitoba.ca

Wen Zhong

Department of Textile Sciences,

Faculty of Human Ecology, 35 Chancellors

Circle, University of Manitoba, Winnipeg,

MB R3T 2N2, Canada

Tel +I 2044749913

Fax + I 2044748137

Email zhong@cc.umanitoba.ca
Abstract: By mimicking the native extracellular matrix, electrospun nanofibrous scaffolds (ENSs) can provide both chemical and physical cues to modulate cell adherence and differentiation and to promote tissue regeneration while retaining bioresorbable and biocompatible properties. In this study, ENSs were developed to deliver multiple biomolecules by loading them into the core-sheath structure and/or by conjugating them to the nanofiber surfaces. In this work, poly(L-lactide)-poly(ethylene glycol)- $\mathrm{NH}_{2}$ and poly(L-lactide) were emulsion electrospun into nanofibers with a core-sheath structure. A model drug, tetracycline hydrochloride, was loaded within the nanofibers. Amino and carboxyl reactive groups were then activated on the fiber surfaces using saturated water vapor exposure and base hydrolysis, respectively. These reactive groups allowed the surface of the ENS to be functionalized with two other bioactive molecules, fluorescein isothiocyanate- and rhodamine-labeled bovine serum albumins, which were used as model proteins. The ENSs were shown to retain their antimicrobial capacity after two functionalization reactions, indicating that multifunctional nanofibers can potentially be developed into functional wound dressings or periodontal membranes or used in more complicated tissue systems where multiple growth factors and anti-infection precautions are critical for the successful implantation and regeneration of tissues.

Keywords: multifunctional nanofibrous scaffold, drug delivery, antibiotics

\section{Introduction}

One promising strategy used in tissue regeneration involves forming bioresorbable and biocompatible materials into scaffolds in a way that mimics or replicates native tissues. Many strategies have been proposed for engineering biomimetic scaffolds, such as freeze-drying, ${ }^{1}$ solvent-free techniques, ${ }^{2}$ and electrospinning methods. ${ }^{3}$ Electrospun nanofibrous scaffolds (ENSs) have recently been gaining interest in the tissue engineering field because of their many advantages.

ENSs provide temporary spaces with a tunable porosity in which cells can exchange metabolites and nutrients with their environment so as to maintain cellular functionality and to aid in the reconstruction of tissues while also maintaining tailored mechanical properties to protect the wound bed from collapse and to avoid mechanical mismatch between scaffolds and host tissues. ${ }^{4}$ By replicating host tissue matrices, ENSs can regulate stem cell differentiation and promote cell ingrowth. ${ }^{5}$ More importantly, ENSs can be fabricated as drug carriers to release therapeutic agents into wounds in a controlled manner instead of direct injections of drugs that are expensive and inefficient. For example, anticancer drugs (such as doxorubicin hydrochloride ${ }^{6}$ and paclitaxel $^{7}$ ) and antibacterial agents (such as cefazolin, ${ }^{8}$ cefoxitin sodium, ${ }^{9}$ and 
tetracycline hydrochloride $[\mathrm{TCH}])^{10}$ have been loaded into nanofibers. These drugs can be randomly distributed in nanofibers ${ }^{11}$ or can be entrapped in the core of the fibers. ${ }^{6,10}$ Co-axial and emulsion electrospinning processes produce nanofibers with core-sheath structures that provide a more sustained release of drugs. ${ }^{6}$

One of the focuses of tissue engineering is the manipulation and regulation of stem cell fate within a hierarchical structure into which cells can attach, spread, differentiate, and proliferate. ${ }^{12}$ Nanofibers can be functionalized with a variety of regulators (such as growth factors, morphogens, antibiotics, or functional groups) to modify the local cell environment niche and to ultimately change cell fate. ${ }^{13-18} \mathrm{Kim}$ and Park ${ }^{19}$ fabricated lysozyme-functionalized nanofibers made of a polycaprolactone and poly(lactide-co-glycolide)$b$-poly(ethylene glycol)- $\mathrm{NH}_{2}$ diblock copolymer. Patel et al ${ }^{18,20}$ fabricated heparin- and basic fibroblast growth factor-functionalized poly(L-lactide) (PLLA) nanofibers by using di- $\mathrm{NH}_{2}$-poly(ethylene glycol) as a linker molecule. The results showed that the laminin-modified nanofiber mats induced neurite outgrowth and promoted cell migration. ${ }^{18,20}$ Interactions between the fiber surfaces and proteins affect the success of scaffold implantation by modulating cell adhesion and immigration, potentially triggering a cascade of foreign body responses and even promoting bacteria adhesion. Poly(ethylene glycol) (PEG) has been demonstrated to prevent nonspecific protein adsorption and to increase circulation time. ${ }^{21,22}$

Despite the large amount of research on functionalized nanofibers, there has been little work on the development of nanofibers with more than two incorporated bioactive molecules. However, multifunctional nanofibers are desirable for applications in wound healing, as they could protect the wound from infection and promote tissue reconstruction. Therefore, in this study, multifunctional PLLA/PLLA- $b$-PEG nanofibers were developed. A model antibiotic, TCH, was loaded into the PLLA/PLLA- $b$-PEG nanofibrous scaffold via emulsion electrospinning. ${ }^{23,24}$ The surfaces of the drugloaded nanofibers were then modified to allow covalent conjugation of bioactive molecules. Two fluorescently tagged bovine serum albumins (BSAs) were used as model proteins for immobilization. Using microorganism susceptibility tests, confocal microscopy, and Fourier transform infrared attenuated total reflectance (FTIR-ATR) analysis, this study showed that multiple proteins were successfully conjugated to the nanofibrous scaffolds. Finally, the conjugation of peptide Arg-Gly-Asp-Ser (RGDS) and platelet-derived growth factor (PDGF)-BB on scaffolds promoted the growth of human dermal fibroblasts (HDFs). The strategy has potential applications in tissue engineering and regenerative medicine.

\section{Materials and methods Materials}

L-lactide and PLLA (molecular weight [MW] $220 \times 10^{3} \mathrm{~g} / \mathrm{mol}$ ) were obtained from Purac USA (Lincolnshire, IL). $\mathrm{NaOH}$ ( $\geq 98 \%$ ), benzyltriethylammonium chloride (BTAC) (98\%), BSA ( $\geq 96 \%$ ), 2-mercaptoethanol, fluorescein isothiocyanate (FITC)-conjugated BSA, rhodamine isothiocyanate, and peptide RGDS were from Sigma-Aldrich (Oakville, ON). Recombinant human PDGF-BB, BODIPY ${ }^{\circledR}$ FL Phallacidin and ToPro $^{\circledR}-3$ were purchased from Invitrogen (Carlsbad, CA). HDF was from ATCC (Manassas, VA). 1-Ethyl-3-(3-dimethyl aminopropyl) carbodiimide hydrochloride (EDC), sulfoN-hydroxysuccinimide (sulfo-NHS), ethylene glycol-bis (succinimidyl succinate) (EGS), TCH ( $\geq 95 \%$ ), dimethyl sulfoxide (DMSO), and snake skin pleated dialysis tubing (MW cutoff $=7000)$ were from Fisher Scientific (Ottawa, ON). PEG $(\mathrm{MW}=5000 \mathrm{Da}$, polydispersity index $[\mathrm{PDI}]=1.03)$ with functional end groups (HO-PEG5000- $\left.\mathrm{NH}_{2}\right)$ was from JenKem Technology USA, Inc (Allen, TX). All reagents were used without further purification. To prepare rhodamineBSA, rhodamine isothiocyanate was first dissolved in DMSO at a concentration of $5 \mu \mathrm{g} / \mu \mathrm{L}$. Rhodamine solution $(50 \mu \mathrm{L})$ was slowly added to $1 \mu \mathrm{L}$ of BSA solution $(1.5 \mu \mathrm{g} / \mu \mathrm{L})$. After overnight reaction at room temperature, the solution was purified in a dialysis bag (7000 MW cutoff) against phosphate-buffered saline (PBS) $(\mathrm{pH} 7.4)$ to remove the residual rhodamine.

For the preparation of PLLA- $b$-PEG-NH ${ }_{2}$, HO-PEG$\mathrm{NH}_{2}$ was dissolved in a mixture of aqueous $\mathrm{NaOH}$ and tetrahydrofuran, and di-tert-butyl dicarbonate $\left(\mathrm{Boc}_{2} \mathrm{O}\right)$

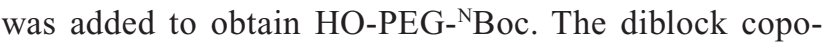
lymer PLLA- $b$-PEG- ${ }^{\mathrm{N}}$ Boc was prepared by ring-opening polymerization of L-lactide in the presence of $\mathrm{HO}-\mathrm{PEG}-{ }^{\mathrm{N}} \mathrm{Boc}$ as a macro-initiator and diethylzinc as a catalyst. PLLA- $b$ PEG- ${ }^{\mathrm{N}}$ Boc was then dissolved in a solvent mixture of $\mathrm{CH}_{2} \mathrm{Cl}_{2}$ and trifluoroacetic acid (TFA) at $0^{\circ} \mathrm{C}$ for 2 hours. TFA and $\mathrm{CH}_{2} \mathrm{Cl}_{2}$ were removed in a vacuum, and the remaining solid was dissolved in a mixture of chloroform and triethylamine. The final PLLA- $b$-PEG-NH $\mathrm{N}_{2}$ product was precipitated out. Gel permeation chromatography revealed that the block copolymer had an $\mathrm{M}_{\mathrm{n}}$ (number average molecular weight) of $20 \mathrm{kDa}$ and a PDI of 1.3, indicating a narrow molecular weight distribution. The nuclear magnetic resonance spectrum is shown in Supplementary Figure 1. 


\section{Electrospun PLLA/PLLA-PEG-NH ${ }_{2}$ nanofibrous scaffolds}

The polymers PLLA and PLLA-PEG-NH $\mathrm{N}_{2}$ at 70:30 w/w, and a surfactant, BTAC ( $5 \% \mathrm{w} / \mathrm{w}$ to polymers), were dissolved in chloroform and electrospun at a concentration of $7.5 \% \mathrm{w} / \mathrm{w}$ at room temperature, at a voltage of $22 \mathrm{kV}$, at a flow rate of $7 \mathrm{~mL} / \mathrm{h}$, and with a distance of $12 \mathrm{~cm}$ between the needle tip and the collector. The morphology of the electrospun nanofibers was examined using scanning electron microscopy (SEM) (Cambridge Stereoscan 120, Cambridge, UK) with accelerating voltage $20 \mathrm{kV}$. Samples were mounted on metal stubs using a double-sided adhesive tape and vacuum-coated with a gold layer prior to examination. To determine the average fiber diameter for each sample, ten fibers from each sample were randomly selected in the SEM images, and fiber diameters were measured at six different points on each fiber by ImageJ (National Institutes of Health, Bethesda, MD) software.

\section{Fabrication of $\mathrm{TCH}$-loaded nanofibers by emulsion electrospinning}

TCH-loaded nanofibers were fabricated via emulsion electrospinning. ${ }^{23,24}$ Briefly, a $1 \mathrm{~mL}$ aqueous solution containing
$3 \% \mathrm{w} / \mathrm{w}$ of TCH (with respect to the polymers) was emulsified in $20 \mathrm{~mL}$ of polymer solution containing $7.5 \% \mathrm{w} / \mathrm{w}$ PLLA/ PLLA-PEG-NH $\mathrm{NH}_{2}$ (with a blend ratio of 70:30 w/w) dissolved in chloroform. The emulsification took place in a homogenizer at $7000 \mathrm{rpm}$ for 20 minutes. During the process of emulsification, the emulsion was placed in an ice bath to minimize the evaporation of chloroform by the homogenizer. To obtain a stable and homogeneous water-in-oil (W/O) emulsion, $5 \% \mathrm{w} / \mathrm{w}$ BTAC (with respect to the polymer) was added to the oily phase prior to emulsification as a surfactant to lower the surface tension of the polymer solution. The homogeneous W/O emulsion was then electrospun to yield TCH-loaded PLLA/ PLLA- $b$-PEG nanofibers.

\section{Surface functionalization of electrospun nanofibers for the immobilization of proteins}

Figure 1 shows the procedure for immobilizing FITC-BSA and rhodamine-BSA onto drug-loaded nanofibers. Briefly, the drug-loaded PLLA/PLLA-PEG-NH ${ }_{2}$ scaffolds were first treated with saturated water vapor for 15 minutes to expose the amino groups on the surface of the fibers. These amino

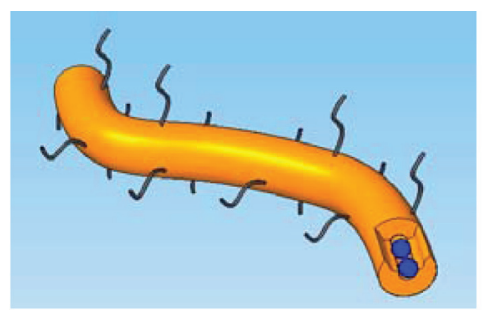

Step 1
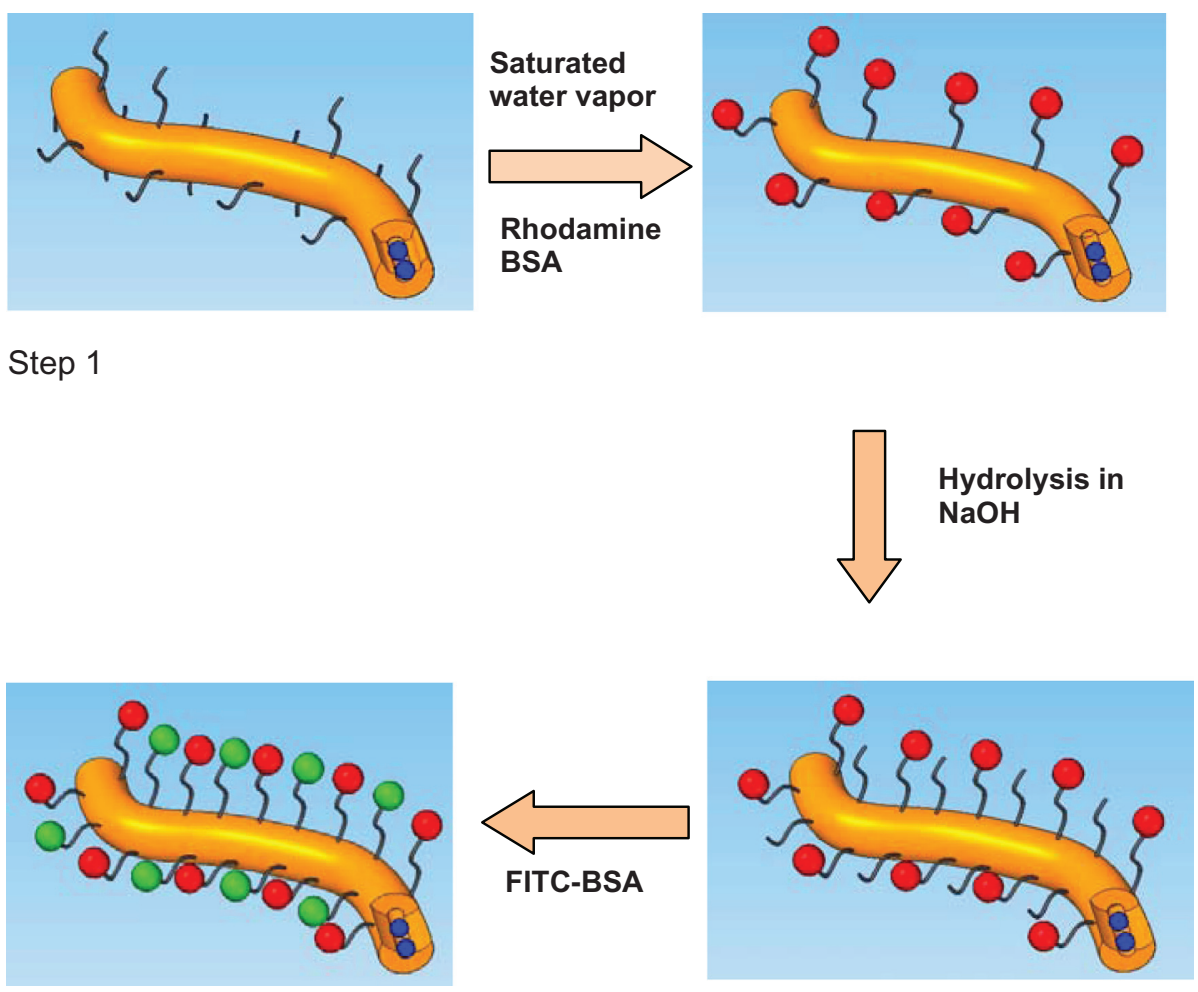

Step 2

Figure I Functionalization procedure of PLLA/PLLA-PEG-NH $\mathrm{N}_{2}$ nanofibers (brown). Step I: Amino groups are activated by exposing nanofibers to saturated water vapor. Step 2: Carboxyl groups are activated by hydrolysis. Blue represents the loaded drug; red is rhodamine BSA; and green is FITC-BSA. Abbreviations: BSA, bovine serum albumin; FITC, fluorescein isothiocyanate; PEG, poly(ethylene glycol); PLLA, poly(L-lactide). 
groups were conjugated to the carboxyl groups of rhodamineBSA via EGS. Each sample (5 mg) was immersed in $20 \mathrm{~mL}$ of DMSO containing $13.7 \mathrm{mg}$ of EGS and gently agitated for 1 hour at room temperature. The scaffolds were then removed and rinsed with distilled water three times and immersed in $20 \mathrm{~mL}$ of PBS containing $4.5 \mathrm{mg}$ of rhodamine-BSA for 30 minutes to yield the functionalized scaffolds. The scaffolds were then washed three times with distilled water $\left(\mathrm{dH}_{2} \mathrm{O}\right)$ and treated with $0.01 \mathrm{M} \mathrm{NaOH}$ for 15 minutes to activate the carboxylic groups on the surface of the nanofibers as a result of surface hydrolysis. ${ }^{18}$ These carboxylic groups were then crosslinked with amine groups in FITC-BSA via EDC. The nanofiber mat was rinsed with $\mathrm{dH}_{2} \mathrm{O}$ and immersed in $20 \mathrm{~mL}$ of PBS solution containing $8 \mathrm{mg}$ of EDC and $22 \mathrm{mg}$ of sulfo-NHS, which was shaken gently and incubated for 15 minutes. Then, $28 \mu \mathrm{L}$ of 2 -mercaptoethanol was added to the solution to quench the residual EDC. A volume of $3 \mathrm{~mL}$ of $1.5 \mathrm{mg} / \mathrm{mL}$ FITC-BSA was added to the solution, and the reaction was allowed to proceed for 2 hours. The samples were rinsed three times with $\mathrm{dH}_{2} \mathrm{O}$ to remove the unreacted BSA from the surface of the nanofibers. SEM and confocal laser scanning microscopy (CLSM) (Olympus IX-70; Olympus Corporation, Tokyo, Japan) were used to characterize the functionalized nanofibers. Supplementary Figure 2 shows the core-shell structure of drug-laden nanofibers after FITC-BSA conjugation only.

\section{In vitro drug release}

The profiles of TCH release from the TCH-loaded ENSs were monitored using an ultraviolet-visible (UV-Vis) spectrometer at a wavelength of $366 \mathrm{~nm}$. Each TCHloaded ENS $(5 \mathrm{mg}$ ) was placed in a dialysis tube (cutoff $\mathrm{MW}=7000)$ and incubated in $30 \mathrm{~mL}$ of $\mathrm{PBS}(\mathrm{Ph} \mathrm{7.4}$, $0.01 \mathrm{M})$ at $37^{\circ} \mathrm{C}$ while the tube was gently shaken. At predetermined times, $6 \mathrm{~mL}$ of the incubation solution was removed, and $6 \mathrm{~mL}$ of fresh $\mathrm{PBS}, \mathrm{pH} 7.4$, was added to the solution. The TCH concentrations in the removed aliquots were then determined using a $\mathrm{TCH}$ standard curve. The cumulative release of TCH was calculated and plotted as a function of the time of incubation.

\section{Antibiotic susceptibility test}

The samples tested for microorganism susceptibility are listed in Table 1. ENS samples $6.0 \mathrm{~mm}$ in diameter were punched from the fibrous assembly. Samples were functionalized with $\mathrm{TCH}$ at $3 \%$, with or without conjugated BSA. A commercially available TCH-sensitive bacteria strain, Staphylococcus aureus ATCC (American Type
Table I Sample names and specifications

\begin{tabular}{lll}
\hline & $\begin{array}{l}\text { Hybrid (PLLA/PLLA- } \\
\text { b-PEG) ENS }\end{array}$ & $\begin{array}{l}\text { Hybrid ENS functionalized } \\
\text { with both rhodamine- } \\
\text { BSA and FITC-BSA }\end{array}$ \\
\hline Blank & $\mathrm{H} 0-\mathrm{I}$ & $\mathrm{H} 0-3$ \\
$3 \% \mathrm{TCH}$ & $\mathrm{H} 3-\mathrm{I}$ & $\mathrm{H} 3-3$ \\
\hline
\end{tabular}

Abbreviations: BSA, bovine serum albumin; ENS, electrospun nanofibrous scaffold; FITC, fluorescein isothiocyanate; PEG, poly(ethylene glycol); PLLA, poly(L-lactide); $\mathrm{TCH}$, tetracycline hydrochloride.

Culture Collection, Seattle, WA) 25923 was used for this test. The samples were placed on agar plates that had been streaked with Staphylococcus aureus and were incubated in an incubator at $37^{\circ} \mathrm{C}$ for 24 hours. The inhibitory effect of each sample was evaluated by measuring the diameter of the clear area around the sample where bacteria growth was inhibited (known as the inhibition zone). The samples were then transferred to fresh bacteria-streaked agar plates to analyze the inhibitory effect provided by the remaining drug within the samples. Each test of antibacterial activity of the samples against Staphylococcus aureus was performed for 4 consecutive days or until the samples had lost their antibacterial ability. The antibacterial experiments were performed in triplicate. All results are expressed as the mean \pm standard deviation of the mean. A $t$-test was used to determine which differences between groups were significant. A $P$-value less than 0.05 was considered significant.

\section{HDF growing on the PDGF- and RGDS- conjugated ENSs}

To investigate the behavior on bioactive molecule immobilized ENSs, the cultivated HDF was seeded on the PDGF-BBand RGDS-conjugated ENS and the control samples without conjugation. The conjugation method was the same as described in the previous section. Scaffolds were sterilized under ultraviolet light for 30 minutes and immersed in $70 \%$ ethanol for 30 minutes. After being cultured for 24 hours, HDFs cultured on various ENSs were fixed with $4 \mathrm{vol} \%$ paraformaldehyde in PBS for 30 minutes, and washed with PBS three times for 5 minutes each. After fixation, the cells were permeabilized by $0.1 \%$ Triton ${ }^{\circledR} \mathrm{X}-100$ (Dow Chemical Company, Midland, MI) in PBS for 10 minutes, and then the cells were rinsed in PBS three times. The cells were incubated in $10 \mu \mathrm{M}$ phallacidin $/ 1 \%(\mathrm{w} / \mathrm{v}) \mathrm{BSA}$ solution for 20 minutes followed by rinsing in PBS three times. The cells were then incubated in $10 \mu \mathrm{M}$ ToPro-3 for 20 minutes, followed by PBS washing three times. The ENSs were dried by air flow and mounted between cover slip and microscope slide and examined by CLSM. 


\section{Results}

\section{Morphology and functionalization of the electrospun nanofibers}

The blank PLLA-PEG-NH $/$ /PLLA (hybrid) nanofibers (641 nm) and blank hybrid ENS functionalized with conjugation $(608 \mathrm{~nm})$ were uniform and smooth on the surface, as shown in Figure 2A and B. Drug-loaded nanofibers without $(740 \mathrm{~nm})$ and with conjugation $(780 \mathrm{~nm})$ are shown in Figure 2C and D. The size of the drug-loaded nanofibers increased slightly, but the surfaces remained smooth with no visible drug crystals.

To test the validity of the immobilization method presented in Figure 1, NHS was coupled to the carboxyl groups of surface hydrolyzed ENS, resulting in the formation of an NHS ester, as shown in Figure 3A, with the amide I band at $1646 \mathrm{~cm}^{-1}$. EGS was conjugated to the amino groups of water vapor-treated ENS to form an amide, which was present at $1646 \mathrm{~cm}^{-1}$, as shown in Figure 3B.

SEM images of the hybrid scaffolds functionalized with two model BSA proteins are shown in Figure 2C. The BSAfunctionalized nanofibers appeared to be thicker than the original nanofibers. This increased thickness may have been caused by the swelling of the nanofibers after their reaction with the BSAs. Confocal microscopy was used to examine the nanofibers conjugated with two fluorescently labeled BSAs. Hybrid nanofibers functionalized with both FITC-BSA and rhodamine-BSA are shown in Figure 4A, B, and C. The green FITC image (Figure 4A), red rhodamine image (Figure 4B), and a merged image (Figure $4 \mathrm{C}$ ) show that the BSAs were present on the surface of the hybrid nanofibers. This result suggests that the two model proteins were immobilized on the surfaces of these nanofibers.
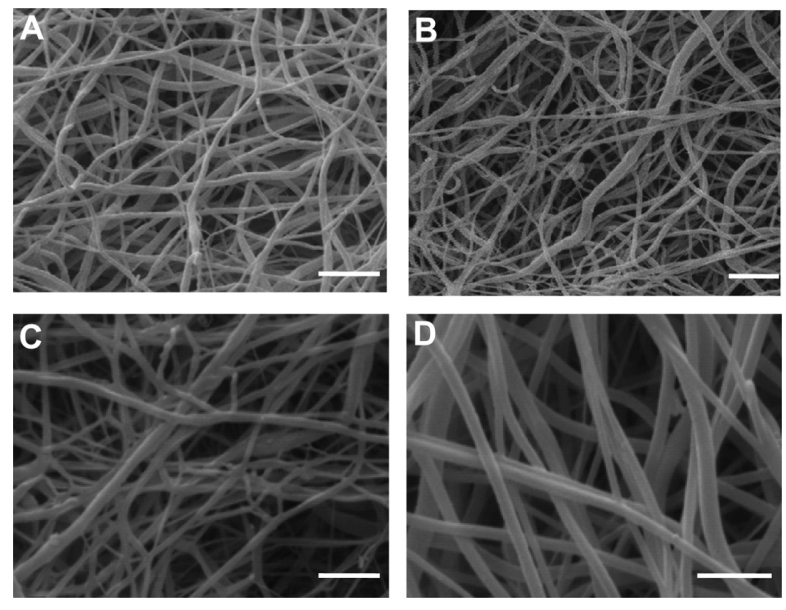

Figure 2 Scanning electron microscopy micrograph of (A) $\mathrm{H} 0-\mathrm{I}$, (B) $\mathrm{H} 0-3$, (C) H3-I, and (D) H3-3. Bar: $2 \mu \mathrm{m}$.

\section{In vitro release of $\mathrm{TCH}$ from drug-loaded scaffolds}

TCH release from ENSs was monitored by UV-Vis spectrometry at a wavelength of $366 \mathrm{~nm}$ to confirm that the drugs could be released in a controlled and sustained manner and to determine whether conjugation of BSA to the scaffold BSA influenced the release rate. The encapsulation rate of TCH was $70 \%$ for ENSs without BSA conjugation (H3-1) and $30 \%$ for ENSs with two conjugated BSAs (H3-3) (Figure 5). $\mathrm{TCH}$ underwent a burst release from H3-1, with nearly $70 \mu \mathrm{g}$ of TCH being released during the first 24 hours. The drug was then released in a slower manner from the ENS during the next 100 hours. The cumulative drug release was $85 \mu \mathrm{g}$. The profiles of TCH release from H3-3 are shown in Figure 5 . In this case, TCH was sustainably slow released from H3-3 fibers over time, and no obvious burst release was observed in the whole incubation time span. There might be two major reasons for the lack of burst release and sustainable drug release. Firstly, the surface BSA coating on the fibers may contribute to this controlled release of drug from the fibers. The other reason is because the reactions in which the proteins were added were performed in aqueous solutions; thus, the burst release of TCH may already have occurred. Therefore, the BSA-conjugated samples had a lower cumulative $\mathrm{TCH}$ release $(45 \mu \mathrm{g})$ compared with that of $\mathrm{H} 3-1$.

\section{Antibiotic susceptibility test}

The antibacterial capacity of TCH-loaded ENSs was evaluated using the microorganism susceptibility test. The effect of surface functionalized on the antibacterial capacity of drugloaded nanofibers was also determined. The diameter of the inhibition zone was used as a measure of the antimicrobial capacities of the nanofiber samples (Figure 6). The results are shown in Figures 6 and 7. The size of the inhibition zone decreased with time. The antibacterial capacities of the drug-loaded nanofibers lasted 6 days for the samples without conjugated BSA (H3-1) and only 3 days for the samples with two conjugated BSAs (H3-3). Thus, H3-1 (no conjugation) had a significantly higher $(P<0.05)$ antibiotic capability than H3-3. This difference may be a result of the aqueous environment used in the BSA functionalization, which may have led to drug loss. The hybrid samples underwent the BSA immobilization process twice, causing a larger amount of TCH loss. However, the samples still keep antibiotic capability, and this drug loss can be compensated for by the incorporation of a larger percentage of drug, which will be done in future studies. 

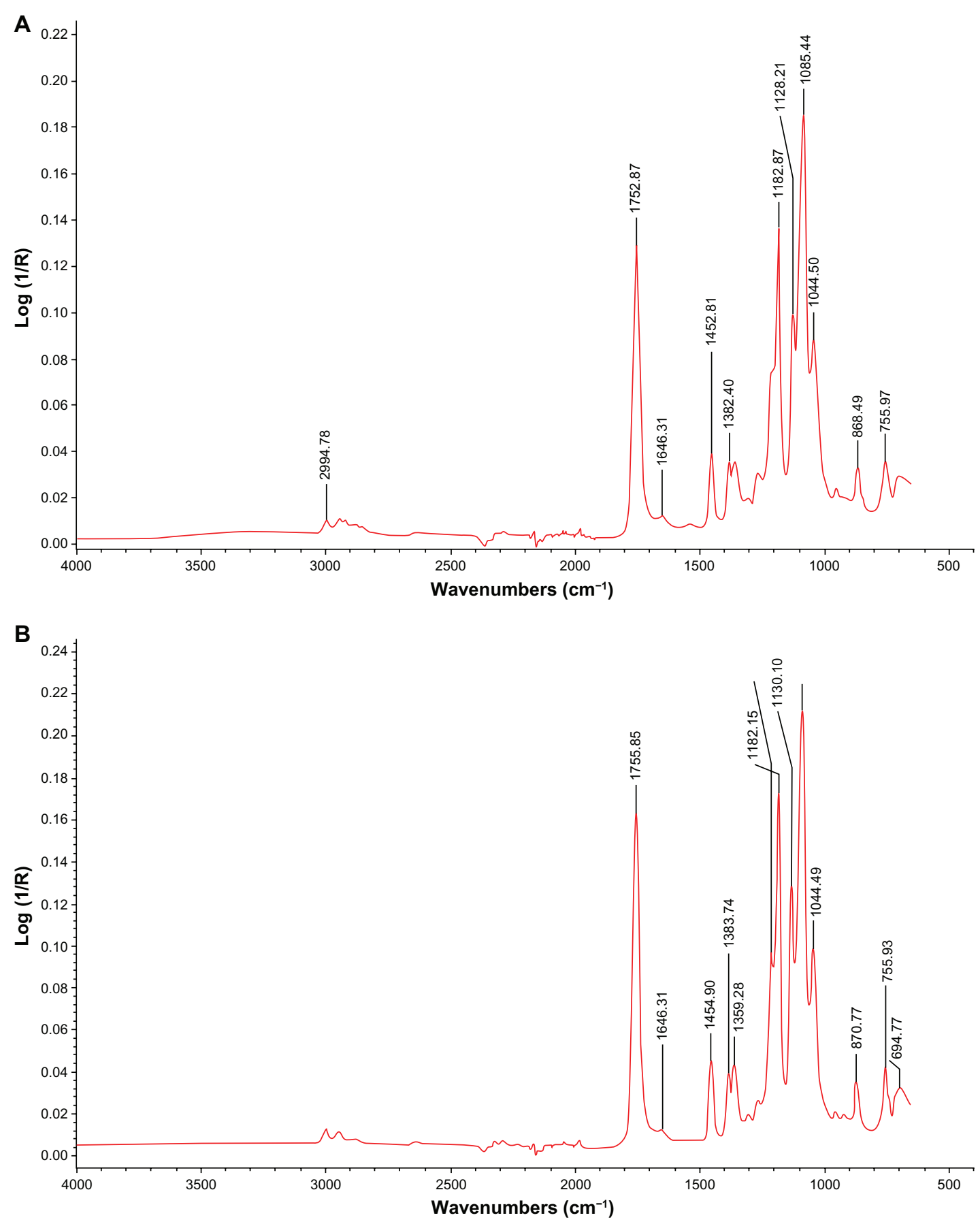

Figure 3 FTIR-ATR spectra of ENSs conjugated with two model agents. (A) A hybrid ENS coupled with NHS by EDC. (B) An ENS coupled with EGS.

Abbreviations: EDC, I-Ethyl-3-(3-dimethyl aminopropyl) carbodiimide hydrochloride; EGS, ethylene glycol-bis(succinimidyl succinate); ENS, electrospun nanofibrous scaffold; FTIR-ATR, Fourier transform infrared attenuated total reflectance; NHS, N-hydroxysuccinimide.

\section{Cell adhesion and proliferation on nanofibrous scaffold}

The HDFs cultivated on ENSs (with and without conjugation of PDGF-BB and RGDS) were immunostained with fluorescent reagents and visualized by confocal microscopy, as shown in Figure 8. The cytoskeleton was stained as green color by phallacidin, and the nuclei were stained as far-red by ToPro-3 and changed to blue color by software (as shown in Figure 8).

\section{Discussion}

ENSs have been described as a promising multiscale biomimetic matrix for tissue engineering. At the microscale level, nanofibers can: (1) mimic the interactions between 

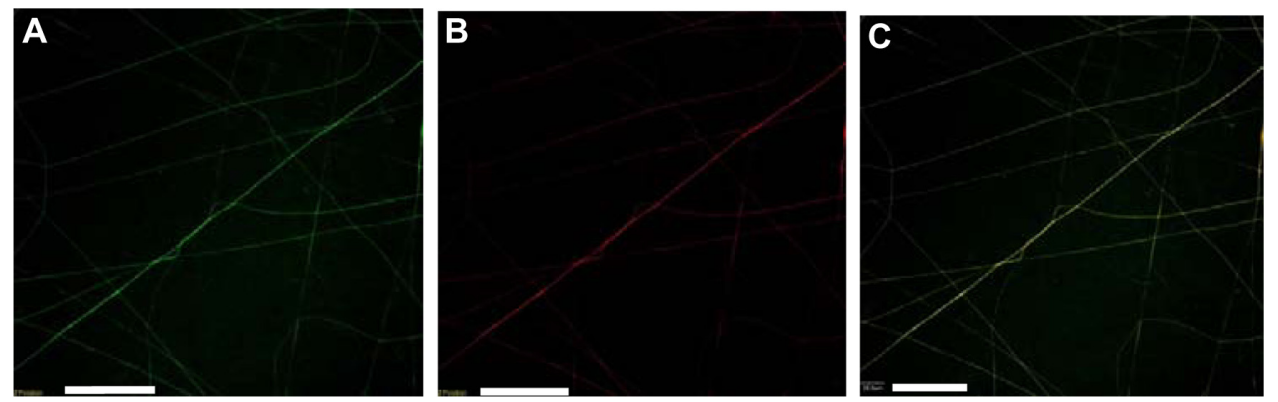

Figure 4 Confocal images of PLLA/PLLA-PEG-NH ${ }_{2}$ nanofibers functionalized with both FITC-BSA and rhodamine-BSA. (A) Image showing FITC-BSA, (B) image showing rhodamine-BSA, and (C) merged $A$ and $B$. Bar: $20 \mu \mathrm{m}$.

Abbreviations: BSA, bovine serum albumin; FITC, fluorescein isothiocyanate; PEG, poly(ethylene glycol); PLLA, poly(L-lactide).

a ligand and a receptor, (2) be patterned to modulate cell differentiation, and (3) act as a nanomedicine that promotes tissue healing and protects the wound bed from bacterial invasion. At the mesoscale level, ENSs can: (1) act as a mechanical regulator that directs cell migration, proliferation, and differentiation; (2) provide a framework for the regeneration of new tissues; (3) serve as a vehicle for cells and growth factors; (4) maintain the wound shape to minimize the deformation of the surrounding tissue; and (5) serve as a barrier to protect against infiltration of the surrounding tissue, which may impede the regeneration process. At the macroscale level, ENSs can act as a tissue mimic with integrated multifunctionality to substitute for lost or diseased tissues.

The presence of multiple growth factors or regulators is a requirement during the tissue healing process, from a developmental biology perspective. For example, bone morphogenetic protein (BMP)-2 promotes bone reconstruction and aids in angiogenesis in the presence of vascular endothelial growth factor (VEGF). VEGF and insulin-like growth factor (IGF)-1 can be delivered together to promote muscle regeneration after ischemic muscle injury. ${ }^{25}$ VEGF administration followed by PDGF-BB addition has been used

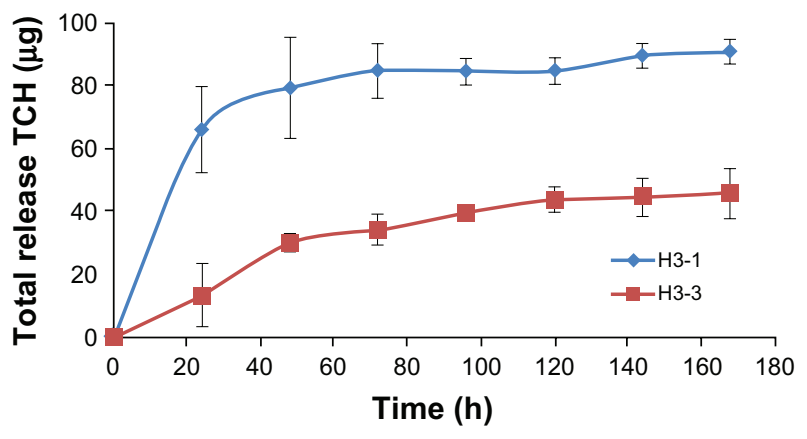

Figure 5 Controlled release from TCH-loaded ENSs with $(\mathrm{H} 3-3)$ and without $(\mathrm{H} 3-\mathrm{I})$ conjugated BSA. All samples were $3 \% \mathrm{TCH}$-loaded ENSs $(n=3)$.

Abbreviations: BSA, bovine serum albumin; ENS, electrospun nanofibrous scaffold; $\mathrm{TCH}$, tetracycline hydrochloride. to improve vascularization. ${ }^{26}$ Recently, a technology was developed to deliver multiple growth factors by sacrificing microsphere-loaded nanofibers (phase I), resulting in the microspheres being entrapped within the nanofiber (phase II) scaffolds. ${ }^{27}$ However, most existing scaffolds for implantation carry no more than two types of therapeutic agents, which may hinder the efficacy of scaffold transplantation.

In this study a multifunctional ENS was constructed using PLLA/PLLA-PEG-NH ${ }_{2}$ that can carry up to three bioactive molecules. Antibiotic-loaded nanofibers were first fabricated with a core-sheath structure using an emulsion electrospinning method. Adhering to the principle of minimal system energy, hydrophilic $\mathrm{NH}_{2}$ groups were designed to be projected into a hydrophilic environment by exposing the nanofibers to water vapor. The model protein rhodamine-BSA was conjugated to the $\mathrm{NH}_{2}$ groups.
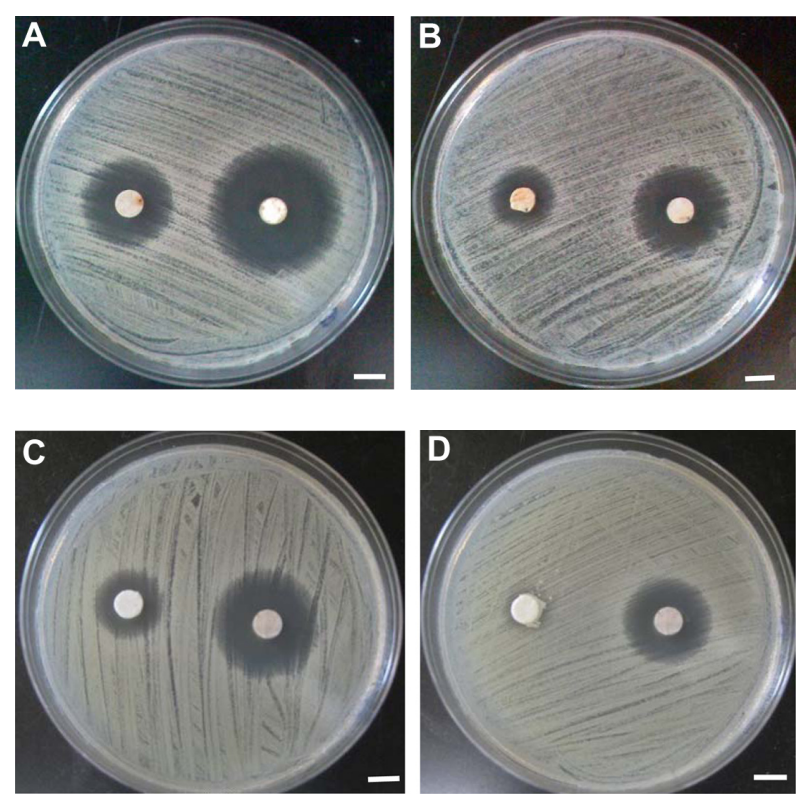

Figure 6 Antibacterial tests of $\mathrm{H} 3-\mathrm{I}$ and H3-3. (A) Day I H3-3 (left) and H3-I (right); (B) day $2 \mathrm{H} 3-3$ (left) and $\mathrm{H3}-\mathrm{I}$ (right); (C) day $3 \mathrm{H} 3-3$ (left) and $\mathrm{H} 3-\mathrm{I}$ (right); and (D) day $4 \mathrm{H3}-\mathrm{I}$ (H3-3 was discarded). Bar: $5 \mathrm{~mm}$. 


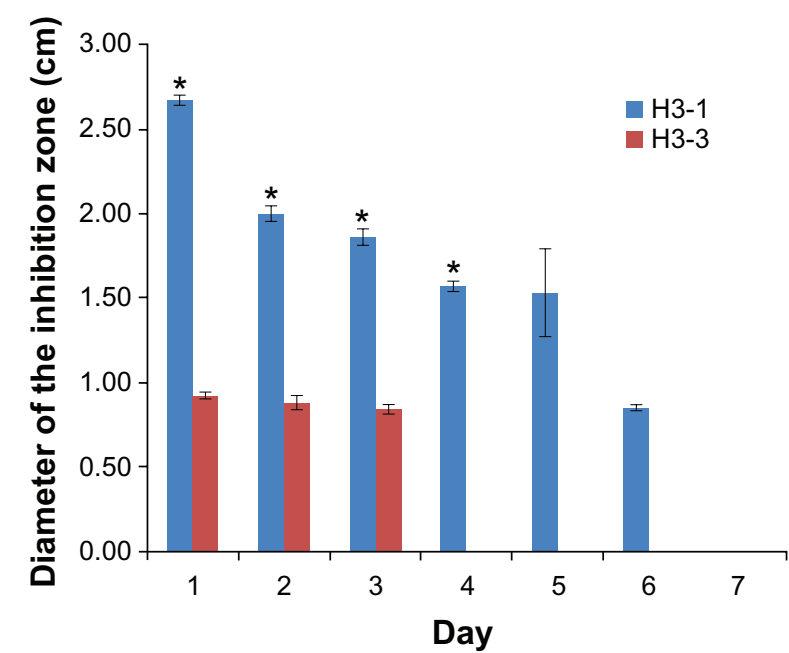

Figure 7 Antibacterial tests of $\mathrm{H} 3-\mathrm{I}$ and $\mathrm{H} 3-3$.

Note: $* P<0.05$ based on the statistical analysis for the inhibition zone tests comparing $\mathrm{H} 3-\mathrm{I}$ and $\mathrm{H} 3-3$ at days I, 2, 3, and 4.

Next, hydrolysis of the nanofiber surface was conducted to activate the carboxylic groups, to which the second model protein, FITC-BSA, was conjugated. The covalent conjugation allows therapeutic agents a more sustainable and controllable release than physical loading. ${ }^{28,29}$ Several applications for the ENS system can be found in the healing process of tissues and organs. This system is suitable for skin repair, where antibacterial properties are crucial for proper healing, and the release of growth factors (ie, PDGF-BB and epidermal growth factor [EGF]) is important for maintaining regenerative capabilities. The system can also be adapted to accelerate bone healing when bones have critical defects by releasing VEGF to promote vascularization, BMP-2 to promote osteogenesis, and BMP-7 to promote both chondroblastic and osteoblastic differentiation. Alternatively, the triple-functionalized scaffold system can be engineered to promote muscle regeneration by delivering VEGF and PDGF-BB to promote angiogenesis and IGF-1 to promote muscle regeneration. Biomaterial surfaces can have profound regulatory effects on stem cell differentiation. ${ }^{30,31}$ For example, a fibronectin-coated surface has been shown to modulate integrin adhesion receptor binding. ${ }^{32}$ Even hydrophilicity is able to control the growth of a stem cell colony. ${ }^{31}$ ENSs can be used to investigate tissue regeneration and stem cell modulation through the surface functionalization of different epitopes (eg, Arg-Gly-Asp, Pro-His-Ser-ArgAsn) along with synergic growth factors.

To present the efficacy of the cell growth on bioconjugated ENSs, PDGF-BB and RGDS were sequentially conjugated to ENSs. HDFs were seeded on scaffolds with and without conjugation. Cell adhesion and morphology are known as indicators for cell growth. RGD peptide can improve cell adhesion by recognizing the specific adhesion receptors of cell membranes, and PGF-BB has been verified in clinics to promote wound healing. When the cells seeded on the PDGF-BB- and RGDS-conjugated ENSs for 24 hours, HDFs extended along polymer fibers and increased cell adhesion area, resulting in cell spreading on the polymer fibrous scaffold. In comparison, the cells on without conjugation ENS for 24 hours migrated and extended only a little bit with a round shape on the scaffold. Figure $8 \mathrm{~A}$ and $\mathrm{B}$ clearly shows the difference between scaffolds with and without conjugation. Furthermore, the therapeutic agents remain active after conjugation from Figure 8.

Although the results and methods of this study are promising, some concerns remain. First, ENSs were fabricated using a PLLA/PLLA- $b$-PEG-NH $\mathrm{N}_{2}$ hybrid. The molecular weight of PLLA- $b$-PEG-NH $\mathrm{N}_{2}$ is about $20 \mathrm{kD}$, which is not appropriate for electrospun nanofibers. The PLLA hybrid and the copolymer increase the uniformity of the electrospun fibers, while decreasing the hydrophilicity of the ENS. Second, it is not clear how the ratio of PLLA to copolymer influences protein immobilization or drug loading. It is important to identify the optimal ratio to achieve the ultimate goal of regeneration. Third, the drug loaded in the study had a low molecular weight. The addition of high molecular weight drugs, such as growth factors, to the nanofiber core-shell structure requires different electrospin parameters. Fourth, protein conjugation leads to a decreasing efficacy of drug release from the ENS. Finally, further cell biological works should be conducted to verify the efficacy in tissue engineering by providing more profound results. These concerns will be important to consider in further development of ENSs for their intended applications and will be addressed in the authors' future work.
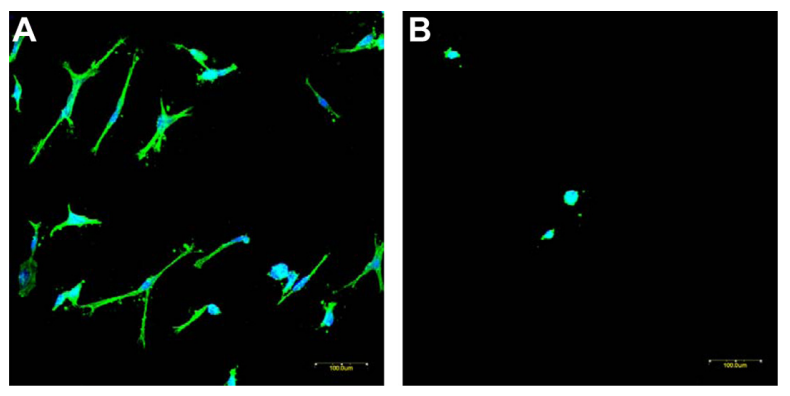

Figure 8 Immunofluorescence staining of human dermal fibroblasts on ENSs of (A) PDGF and RGDS conjugated and (B) blank. Images were recorded by a confocal microscope. The same magnification was used for both pictures. Bar: $100 \mu \mathrm{m}$. Abbreviations: ENS, electrospun nanofibrous scaffold; PDGF, platelet-derived growth factor; RGDS, Arg-Gly-Asp-Ser. 


\section{Conclusion}

In this work, multifunctional ENSs were developed that incorporated the antibacterial agent $\mathrm{TCH}$ and were surface functionalized with two different bioactive molecules. TCH was loaded into PLLA/PLLA-PEG- $\mathrm{NH}_{2}$ nanofibers by emulsion electrospinning and was released from the nanofibers in a sustained manner. FTIR-ATR spectra and CLSM images showed that two fluorescently labeled BSAs could be successfully immobilized on the surface of the modified drug-loaded nanofibers, and the resulting nanofibrous mat still retained its antibacterial properties. This novel material may have potential applications in wound care and tissue engineering, which require multifunctional materials that have antimicrobial properties and also promote wound healing or tissue regeneration.

\section{Acknowledgments}

This work is supported by Natural Sciences and Engineering Research Council of Canada (NSERC) Discovery Grant, NSERC Research and Tools Grant, Children's Hospital Foundation of Manitoba, Manitoba Medical Service Foundation, and Andison Family Foundation.

\section{Disclosure}

The authors declare no conflicts of interest in this work.

\section{References}

1. Yannas IV, Lee E, Orgill DP, Skrabut EM, Murphy GF. Synthesis and characterization of a model extracellular matrix that induces partial regeneration of adult mammalian skin. Proc Natl Acad Sci U SA. 1989; 86(3):933-937.

2. Mooney DJ, Baldwin DF, Suh NP, Vacanti JP, Langer R. Novel approach to fabricate porous sponges of poly(D,L-lactic-co-glycolic acid) without the use of organic solvents. Biomaterials. 1996;17(14):1417-1422.

3. Nerurkar NL, Baker BM, Sen S, Wible EE, Elliott DM, Mauck RL. Nanofibrous biologic laminates replicate the form and function of the annulus fibrosus. Nat Mater. 2009;8(12):986-992.

4. Hashi CK, Zhu Y, Yang GY, et al. Antithrombogenic property of bone marrow mesenchymal stem cells in nanofibrous vascular grafts. Proc Natl Acad Sci U S A. 2007;104(29):11915-11920.

5. Xie J, Willerth SM, Li X, et al. The differentiation of embryonic stem cells seeded on electrospun nanofibers into neural lineages. Biomaterials. 2009;30(3):354-362.

6. Xu X, Chen X, Ma P, Wang X, Jing X. The release behavior of doxorubicin hydrochloride from medicated fibers prepared by emulsionelectrospinning. Eur J Pharm Biopharm. 2008;70(1):165-170.

7. Ranganath $\mathrm{SH}$, Wang $\mathrm{CH}$. Biodegradable microfiber implants delivering paclitaxel for post-surgical chemotherapy against malignant glioma. Biomaterials. 2008;29(20):2996-3003.

8. Katti DS, Robinson KW, Ko FK, Laurencin CT. Bioresorbable nanofiberbased systems for wound healing and drug delivery: Optimization of fabrication parameters. J Biomed Mater Res B Appl Biomater. 2004;70(2): 286-296.

9. Kim K, Luu YK, Chang C, et al. Incorporation and controlled release of a hydrophilic antibiotic using poly(lactide-co-glycolide)-based electrospun nanofibrous scaffolds. J Control Release. 2004;98(1):47-56.
10. He CL, Huang ZM, Han XJ, Liu L, Zhang HS, Chen LS. Coaxial electrospun poly(L-lactic acid) ultrafine fibers for sustained drug delivery. J Macromol Sci B. 2006;45(4):515-524.

11. Xie J, Tan RS, Wang CH. Biodegradable microparticles and fiber fabrics for sustained delivery of cisplatin to treat $\mathrm{C} 6$ glioma in vitro. $J$ Biomed Mater Res A. 2008;85(4):897-908.

12. Huebsch N, Mooney DJ. Inspiration and application in the evolution of biomaterials. Nature. 2009;462(7272):426-432.

13. Chew SY, Mi R, Hoke A, Leong KW. Aligned protein-polymer composite fibers enhance nerve regeneration: a potential tissueengineering platform. Adv Funct Mater. 2007;17(8):1288-1296.

14. Luong-Van E, Grondahl L, Chua KN, Leong KW, Nurcombe V, Cool SM. Controlled release of heparin from poly(epsilon-caprolactone) electrospun fibers. Biomaterials. 2006;27(9):2042-2050.

15. Liao IC, Chew SY, Leong KW. Aligned core-shell nanofibers delivering bioactive proteins. Nanomedicine. 2006;1(4):465-471.

16. Zhang YZ, Wang X, Feng Y, Li J, Lim CT, Ramakrishna S. Coaxial electrospinning of (fluorescein isothiocyanate-conjugated bovine serum albumin)-encapsulated poly(epsilon-caprolactone) nanofibers for sustained release. Biomacromolecules. 2006;7(4):1049-1057.

17. Choi JS, Leong KW, Yoo HS. In vivo wound healing of diabetic ulcers using electrospun nanofibers immobilized with human epidermal growth factor (EGF). Biomaterials. 2008;29(5):587-596.

18. Patel S, Kurpinski K, Quigley R, et al. Bioactive nanofibers: synergistic effects of nanotopography and chemical signaling on cell guidance. Nano Letters. 2007;7(7):2122-2128.

19. Kim TG, Park TG. Surface functionalized electrospun biodegradable nanofibers for immobilization of bioactive molecules. Biotechnol Prog. 2006;22(4):1108-1113.

20. Koh HS, Yong T, Chan CK, Ramakrishna S. Enhancement of neurite outgrowth using nano-structured scaffolds coupled with laminin. Biomaterials. 2008;29(26);3574-3582.

21. Lensen MC, Mela P, Mourran A, et al. Micro- and nanopatterned star poly(ethylene glycol) (PEG) materials prepared by UV-based imprint lithography. Langmuir. 2007;23(14):7841-7846.

22. Groll J, Haubensak W, Ameringer T, Moeller M. Ultrathin coatings from isocyanate terminated star PEG prepolymers: patterning of proteins on the layers. Langmuir. 2005;21(7):3076-3083.

23. Qi HX, Hu P, Xu J, Wang, AJ. Encapsulation of drug reservoirs in fibers by emulsion electrospinning: morphology characterization and preliminary release assessment Biomacromolecules. 2006;7(8):2327-2330.

24. Xu XL, Zhuang XL, Chen XS, Wang XR, Yang LX, Jing XB. Preparation of core-sheath composite nanofibers by emulsion electrospinning. Macromol Rapid Commun. 2006;27(19):1637-1642.

25. Borselli C, Storrie H, Benesch-Lee F, et al. Functional muscle regeneration with combined delivery of angiogenesis and myogenesis factors. Proc Natl Acad Sci U SA. 2010;107(8):3287-3292.

26. Richardson TP, Peters MC, Ennett AB, Mooney DJ. Polymeric system for dual growth factor delivery. Nat Biotechnol. 2001;19(11);1029-1034.

27. Ionescu LC, Lee GC, Sennett BJ, Burdick JA, Mauck RL. An anisotropic nanofiber/microsphere composite with controlled release of biomolecules for fibrous tissue engineering. Biomaterials. 2010;31(14): 4113-4120.

28. Tayalia P, Mooney DJ. Controlled growth factor delivery for tissue engineering. Adv Mater. 2009;21(32-33):3269-3285.

29. Kuhl PR, Griffith-Cima LG. Tethered epidermal growth factor as a paradigm for growth factor-induced stimulation from the solid phase. Nat Med. 1996;2(9):1022-1027.

30. Villa-Diaz LG, Nandivada H, Ding J, et al. Synthetic polymer coatings for long-term growth of human embryonic stem cells. Nat Biotechnol. 2010;28(6):581-583.

31. Shapiro MG, Westmeyer GG, Romero PA, et al. Directed evolution of a magnetic resonance imaging contrast agent for noninvasive imaging of dopamine. Nat Biotechnol. 2010;28(3):264-270.

32. Keselowsky BG, Collard DM, Garcia AJ. Integrin binding specificity regulates biomaterial surface chemistry effects on cell differentiation. Proc Natl Acad Sci U SA. 2005;102(17):5953-5957. 


\section{Supplementary figures}

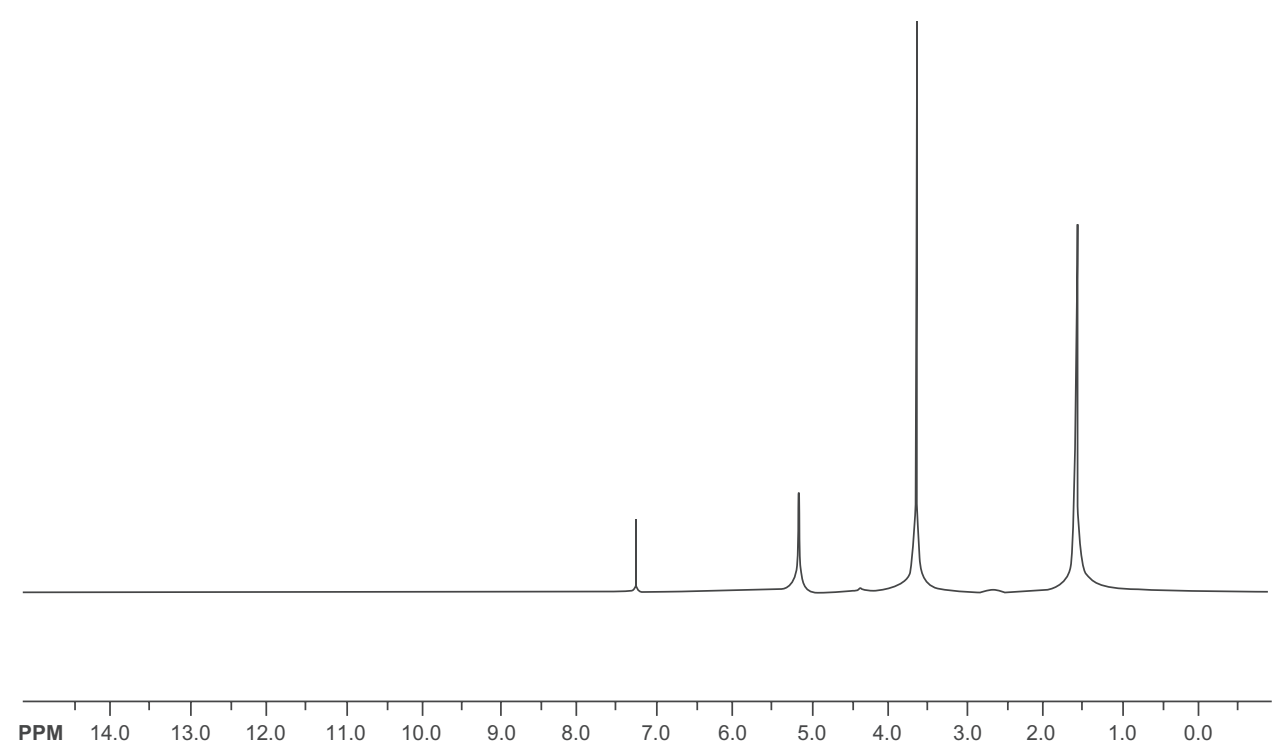

Figure SI Nuclear magnetic resonance spectrum of the PLLA-b-PEG-NH $\mathrm{N}_{2}$ block copolymer.

Notes: The peak at $\delta 5.1$ corresponds to the $\mathrm{CH}$ groups in the PLA blocks; the peak at $\delta 3.6$ corresponds to the $\mathrm{CH}_{2}$ groups in the PEG blocks; and the peak at $\delta \mathrm{I} .6$ corresponds to the $\mathrm{CH}_{3}$ groups in the PLA block.

Abbreviations: PEG, poly(ethylene glycol); PLLA, poly(L-lactide).

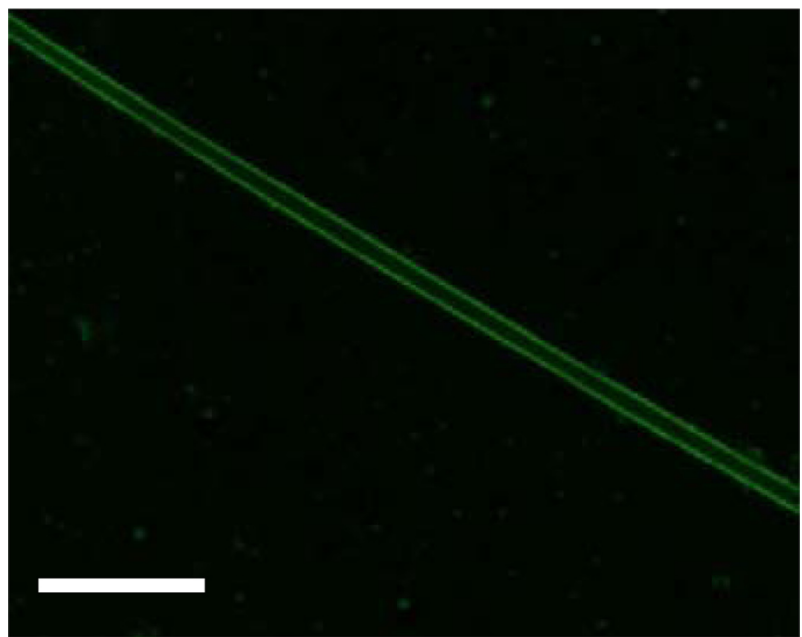

Figure S2 Confocal image of the drug-laden nanofiber with FITC-BSA conjugation only. Bar: $5 \mu \mathrm{m}$.

Abbreviations: BSA, bovine serum albumin; FITC, fluorescein isothiocyanate.

International Journal of Nanomedicine

\section{Publish your work in this journal}

The International Journal of Nanomedicine is an international, peerreviewed journal focusing on the application of nanotechnology in diagnostics, therapeutics, and drug delivery systems throughout the biomedical field. This journal is indexed on PubMed Central, MedLine, CAS, SciSearch $\AA$, Current Contents ${ }^{\circledR} /$ Clinical Medicine,
Journal Citation Reports/Science Edition, EMBase, Scopus and the Elsevier Bibliographic databases. The manuscript management system is completely online and includes a very quick and fair peer-review system, which is all easy to use. Visit http://www.dovepress.com/ testimonials.php to read real quotes from published authors.

Submit your manuscript here: http://www.dovepress.com/international-journal-of-nanomedicine-journal 